\title{
Bleak prospects for physics research council
}

London. Britain's Particle Physics and Astronomy Research Council (PPARC), set up two years ago as the main channel of funding for basic research in these two disciplines, has warned that a lack of new programmes resulting from pressures on government spending means that Britain could be in danger of dropping out of the top league in science.

In evidence presented to an inquiry on the council being carried out by the House of Commons Select Committee on Science and Technology, PPARC points out that, because of these pressures, it has been able to launch virtually no major new scientific projects since coming into existence. The main exception is its commitment to participate in the construction of the Large Hadron Collider (LHC) at the European Laboratory for Particle Physics (CERN).

In astronomy, for example, it has had to turn down an invitation to contribute a key sensor to a Japanese space-based astronomy mission, and to limit severely its participation in the joint construction with Germany of a gravitational wave observatory. It has also been unable to find additional money to develop experiments with an underground detector for particles that may account for the missing 'dark matter' in the Universe.

"There has been a form of planning blight hanging over all our programmes," says Ken Pounds, PPARC's chief executive officer and professor of radioastronomy at the University of Leicester. "The analogy that one colleague has drawn is that until recently we have been driving toward the cliff edge, now we are driving along the cliff edge."

PPARC does not blame its problems entirely on the government. One difficulty has been the increasing costs of its subscription to CERN, the European Laboratory for Particle Physics, due to the fall in value of the pound against the Swiss franc (see Nature 379, 286; 1996). Another has been the extent to which its hands have been tied by various commitments - such as that towards the Gemini telescope - made in the final days of its predecessor, the Science and Engineering Research Council.

At the same time, however, PPARC quotes two additional factors in its evidence to the select committee. It acknowledges that its plight is partly due to decisions taken to enhance its programmes in education and training and in building links to industry, as well as to "the failure, so far, of any additional bids to government for new funds" (with the exception of ring-fenced allocation for CERN exchange rate variations).

PPARC is unlikely to gain sympathy from all other sectors of the research community, particularly from those who feel that Britain still spends too much on 'big science'. Giving oral evidence to the select committee last week, Sir John Cadogan, the director general of research councils, claimed that, on the basis of a review he had carried out last year, "the majority of the science base does not believe that particle physics deserves its present level of funding".

But PPARC's response is to point out that, in relative terms, its share of total science funding has dropped significantly in recent years. Figures presented to the committee show that, despite an increase of about 53 per cent in real terms over the past 20 years, Britain's spending on science, total expenditure on particle physics and astronomy has fallen by 32 per cent during this period - and the rising costs of international subscriptions means that domestic spending has dropped even further, by 53 per cent.

At the same time, the council claims it has evidence to show that "UK research productivity in most PPARC areas exceeds that of our major competitors". The council's main concern is that restrictions in the domestic budget mean that it is able to participate in international programmes at only about half the level that it should be doing on the basis of its contribution to the costs of major facilities such as the LHC.

It also expresses concern at the amount of management time and effort being required from a reduced number of headquarters staff to participate in a range of initiatives launched by the Office of Science and Technology (OST), including management reviews, the Technology Foresight Programme and the so-called ROPAs awards scheme. Ironically, it only received two applications for such awards, designed to stimulate academic/industry collaboration, in 1995 , neither of which was judged by outside assessors to meet the criteria laid down for such awards by the OST.

"PPARC is currently maintaining a strong science programme in particle physics, planetary science and astronomy, but these opportunities are based largely on earlier investments," the research council warns. "Severe funding pressures on PPARC's domestic budget is now limiting future investment which will increasingly threaten the health of the research communities into the next century."

David Dickson

\section{Leviathan telescope set to rise again}

London. A giant 150-year-old telescope, believed to be the world's largest when it was built in 1845, is to be rebuilt at its original site in the grounds of a seventeenth century castle in Ireland, the proposed location of a new Historic Science Centre.

The 72-inch Leviathan (right), which had a focal length of 54 feet, was built and erected by William Parsons, third Earl of Rosse and one-time president of the Royal Society, at the family estate of Birr Castle in County Offaly.

The Leviathan took 20 years to complete and cost $£ 30,000$. It weighed more than 150 tonnes and needed four men to operate it. Parsons, who became a member of parliament at the age of 22 , constructed the 4-tonne mirror himself. The rest of the telescope was built with the help of his servants and other local people.

A grandson dismantled the telescope in 1908, when it became old and rickety. The IRE3-million (US\$4.67million) reconstruction is being supervised by the present Earl of Rosse. The mirror will be made by the optical department at University College, London, and the telescope is expected to be completed by March 1997.

Despite Ireland's often unclear weather, Parsons managed to make a 